\title{
QUÉ SE TRADUCE: LITERATURA Y OTROS LIBROS JAPONESES EN ESPAÑA, 1904-2014
}

\author{
WhAT IS TRANSLATED: JAPANESE LITERATURE AND OTHER BOOKS IN SPAIN, 1904-2014 \\ QU'EST-CE QU'ON TRADUIT ? LITTÉRATURE ET DES AUTRES OEUVRES JAPONAISES \\ EN ESPAGNE, 1904-2014
}

\author{
Alba Serra-Vilella \\ Doctora en Traducción y Estudios \\ Interculturales, Universitat Autònoma \\ de Barcelona (UAB), España. \\ Profesora asociada, Departamento \\ de Traducción e Interpretación y \\ Estudios de Asia Oriental, Universitat \\ Autònoma de Barcelona (UAB), \\ Barcelona, España. \\ alba.serra@uab.cat \\ https://orcid. \\ org/0000-0002-0705-308X
}

\begin{abstract}
RESUMEN
La traducción del japonés en España ha sido poco estudiada desde una perspectiva histórica, especialmente en lo que respecta a los libros no literarios. Este estudio supone una contribución a este ámbito, al aportar datos sobre cómo ha sido la traducción de libros japoneses en España. Un amplio corpus, que abarca las traducciones de 1904 a 2014, nos permite observar el porcentaje de traducciones literarias y de otros géneros que se han llevado a cabo, las temáticas en ellas tratadas, además de los autores más traducidos en este país. Las observaciones muestran que las temáticas que cuentan con más traducciones (libros infantiles, artes marciales, religión, empresa y dibujo, en ese orden) coinciden con algunas de las manifestaciones de la cultura japonesa más extendidas en España; por lo tanto, se confirma la hipótesis de que la selección de obras que se traducen en este país se relaciona con las imágenes culturales existentes sobre Japón. Además, se observa la interrelación entre el sistema literario español y otros sistemas a nivel nacional e internacional. Los resultados sugieren que se debe prestar más atención a la traducción de los libros no literarios como parte de los procesos de formación de imágenes culturales.
\end{abstract}

Palabras clave: historia de la traducción, libros japoneses, literatura japonesa, traducción en España, traducción japonés-español.

\section{Abstract}

The translation from Japanese in Spain has not been amply studied from a historical perspective. This study is a contribution to the field in the sense that it offers data about how translation of Japanese books has been conducted in Spain. A wide corpus of translations, from 1904 to 2014, sheds light on the percentage of translations that have been done on literary and other kinds of books, the topics of these books, and the authors most translated in Spain. The observations show that the topics with a higher number of translations (children's books, martial arts, religion, business and drawing; in that order), coincide with some of the most widespread manifestations of Japanese culture in Spain. These data confirm the hypothesis that the selection of books that are translated in Spain is related to existing cultural images about Japan. Furthermore, they confirm the correla-
Este trabajo fue realizado en el marco del grupo de investigación GREGAL: Circulación Cultural Japón-Corea-Cataluña (2017 SGR 1596) de la Universitat Autònoma de Barcelona.

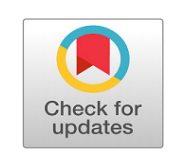

Recibido: 2020-10-28 / Aceptado: 2021-02-02 / Publicado: 2021-05-05

https://doi.org/10.17533/udea.ikala.v26n2a09 
tion between the Spanish literary system and other national and international systems. The results suggest that more attention should be paid to translation of non-literary books as a part of the processes of cultural image making.

Keywords: Translation history, Japanese books, Japanese literature, translation in Spain, Japanese-Spanish translation.

\section{RÉSUMÉ}

La traduction du japonais en Espagne a été peu étudiée d'un point de vue historique, en particulier en ce qui concerne les livres non littéraires. La présente étude constitue une contribution qui fournit des données sur la manière dont la traduction de livres japonais a été effectuée en Espagne. Un large corpus de traductions, de 1904 à 2014, permet d'observer le pourcentage de traductions littéraires et celles d'autres genres qui ont été réalisées, les sujets y traités, ainsi que les auteurs les plus traduits en Espagne. Ces analyses indiquent que les sujets qui ont le plus de traductions (livres pour enfants, arts martiaux, religion, entreprise et dessin ; dans cet ordre) coïncident avec certaines des manifestations les plus répandues de la culture japonaise en Espagne. Par conséquent, ces données confirment l'hypothèse que la sélection des œuvres qui sont traduites dans ce pays est liée aux images culturelles existantes du Japon. De plus, elles renforcent l'interrelation entre le système littéraire espagnol et d'autres systèmes au niveau national et international. Les résultats suggèrent qu'une plus grande attention devrait être accordée à la traduction et aux livres non littéraires au sein des processus de formation d'images culturelles.

Mots-clés: histoire de la traduction ; livres japonais ; littérature japonaise ; traduction en Espagne; traduction japonais-espagnol.

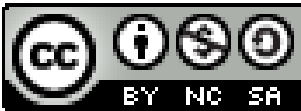




\section{Introducción}

Hay numerosos estudios sobre historia de la traducción en diferentes países y lenguas, pero la mayoría se centra en la literatura. En cambio, hay poca investigación sobre la traducción de libros no literarios y aún menos estudios en los que se trate sobre la temática de estos libros. Por ejemplo, el trabajo de Zhou y Sun incluye un análisis de temáticas, pero es solamente en un apartado de su trabajo (2017, pp. 112-114).

A partir de esta observación, en este artículo analizamos los libros japoneses publicados en España entre 1904 y 2014. El objetivo es doble: por una parte, ofrecer información detallada sobre qué se traduce y, por otra, analizar qué imagen del otro ofrecen las temáticas de los libros traducidos. El análisis se centra, así, en las temáticas de los libros no literarios y, en menor medida, en los autores más traducidos.

Basándonos en la idea de que una parte de la imagen del otro que se ofrece en la producción editorial traducida empieza en el momento de la selección de obras a traducir, la hipótesis de partida es que esta selección muestra una tendencia a determinados temas que se relacionan con la imagen preexistente de ese país.

Además, es conocido que la traducción es un elemento clave de la comunicación e intercambios entre culturas y, por lo tanto, el estudio de la historia de la traducción puede ser muy útil para mejorar la comprensión de los contactos interculturales. En este sentido, con este estudio también pretendemos comprobar la utilidad y la necesidad de relacionar la traducción con el contexto sociocultural en el que se produce, para comprender mejor los procesos de comunicación interculturales.

En síntesis, este estudio supone una contribución al ámbito de la historia de la traducción, para conocer mejor la traducción de libros japoneses en España, incluida la traducción literaria. Nuestro trabajo se centra, en últimas, en comprender qué se ha traducido y explicar cómo se relaciona con el contexto histórico.

\section{Marco teórico}

Hay una falta de estudios en historia de la traducción y una necesidad de desarrollar más este campo, como lo destacan Pym (1998) y Lafarga (2005). Pym (1998, pp. 15-18) sintetiza en tres puntos el interés de esta área de estudio: para describir culturas concretas, para la creación de políticas culturales y para ayudar a los traductores a entender su papel en la formación y la transformación de las culturas. Orozco asimismo señala esta cuestión, cuando afirma que la traducción es "la creación de un texto que establece un puente de comunicación entre toda la humanidad no solo en el ámbito geográfico sino también histórico" (2000, p. 74). Por su parte, Delisle enumera más de veinte funciones de la traducción, como, por ejemplo, "identitaria" y "formadora" (2003, p. 224), mostrando la importancia de investigar este ámbito desde una óptica histórica. Adicionalmente, D'Hulst (2010, p. 399) y Pym (1998, pp. 5-6) organizan la variedad de posibles objetos de estudio de esta disciplina, siguiendo las preguntas que Cicerón y otros habían aplicado a la oratoria.

La traducción pone en contacto dos culturas y, por lo tanto, es previsible que las relaciones de poder entre ellas (más de dos en el caso de la traducción indirecta) se vean reflejadas en el método de traducción y otras variables que influyen en el proceso de traducción y en el resultado. Si pensamos la traducción como una parte de los mecanismos de comunicación y de formación de imágenes culturales, esta perspectiva nos ayuda a entender fenómenos concretos, como los temas escogidos para traducir.

La teoría del polisistema de Even-Zohar usa el concepto de polisistema como una red de sistemas, enfatizando en "una concepción del sistema como algo dinámico y heterogéneo" (Even-Zohar, 2017 , p. 10) y define sistema como "un conjuntode-relaciones cerrado, en el que los miembros reciben su valor de sus respectivas oposiciones" y, a 
la vez, "una estructura abierta que consiste en varias redes-de-relaciones de este tipo que concurren" (Even-Zohar, 2017, p. 11), lo cual resulta mucho más útil para el análisis que la simple acumulación de fenómenos individuales, pues los sistemas permiten inferir leyes o normas. Este autor afirma que los diferentes sistemas (por ejemplo, el sistema literario de cada país) no se encuentran en posición de igualdad, sino que existen jerarquías entre ellos; hay unos elementos centrales y otros periféricos. EvenZohar (2017, p. 90) sostiene que, en las literaturas que ocupan una posición periférica, la traducción es una fuente de innovación y de ampliación de repertorio para el sistema literario local. El presente trabajo se centra en los libros no literarios, pero esta afirmación se puede relacionar con el hecho de que las materias de los libros que se eligen para traducir pueden aportar novedades respecto a la imagen del país de proveniencia, en este caso Japón (lo cual supondría una fuente de innovación) o, por contra, pueden reforzar las imágenes preexistentes.

El hecho de relacionar la traducción con el contexto en que se ha producido es común en muchos enfoques descriptivos de la traducción, fundados en la teoría del polisistema (por ejemplo, Marín Lacarta, 2012, y Torres Simón, 2013), o que utilizan diversa terminología (por ejemplo, el estudio de Gil-Bardají (2009) usa los conceptos texto, contexto y pretexto de Widdowson (2004), y el de Mangiron (2006) usa el término "contexto"). Lo que nos parece interesante de la teoría del polisistema es que pone de relieve las relaciones de poder entre culturas, y cómo las situaciones económicas o políticas entre diferentes países y culturas pueden influir en las traducciones.

A partir de los contactos entre países se forman imágenes culturales que en ocasiones simplifican al Otro y se repiten como estereotipos, que además de considerarse generalmente como negativos (Amossy, 1991, p. 35), se relacionan con jerarquías y dominación (Amossy, 1991, p. 48; Terol, 2008, p. 226). En el ámbito de los estudios literarios, Pageaux propone una metodología de análisis de la imagen que incluye, entre otros aspectos, el análisis de la selección de elementos culturales que derivan en una imagen determinada (1995, p. 145).

Para el caso, existen varios trabajos que analizan la imagen de Japón en España a través de la prensa, como los de Moya (2019), Ojeda (2017) e Iglesias (2019). Destaca el último por su profundidad y magnitud temporal, que repasa las imágenes sobre Japón que circulan en la prensa española desde hace un siglo, abordando los tópicos y estereotipos más comunes. Su exhaustivo análisis nos ha sido útil para compararlo con los datos de publicaciones de distintas materias y comprobar si existen puntos en común.

Entre los condicionantes que influyen en la selección de obras, o más concretamente de autores, cabe destacar los premios literarios y en especial el premio Nobel. Algunos autores manifiestan la influencia de este premio en la selección de obras que se traducen en España, concretamente desde el chino (Marin-Lacarta, 2018, p. 311) y el árabe (El Bohdidi, 2017, p. 278). Este estudio nos permitirá comprobar si este puede ser un condicionante en el caso de la traducción del japonés al español.

Por último, queremos apuntar también brevemente a la presencia de la mujer en la traducción del japonés. Hay estudios, como el de Serra-Vilella (en prensa), que analizan la imagen de la mujer en las cubiertas de los libros, llegando a la conclusión de que esta aparece más como objeto que como sujeto, en consonancia con las reflexiones sobre la representación de la mujer en el orientalismo (Said, 1978, pp. 207-208) y con la imagen de sumisión que prevalece en la representación de la mujer japonesa en los medios españoles (Iglesias, 2019, p. 507). No es objeto de este estudio ahondar en esta materia, pero hemos considerado apropiado fijarnos en el sexo de los autores más traducidos. Una baja representación femenina entre los escritores más traducidos podría tener relación con las desigualdades aún existentes en las sociedades de partida y de llegada de las traducciones. En el caso de España, en las inscripciones del número estándar internacional de libros (International 
Standard Book Number, ISBN) de 2018, el número de autores varones es aproximadamente el doble que de mujeres (España, Ministerio de Educación, Cultura y Deporte - MECD—, 2019, p. 24), y en los libros de texto destaca la ausencia de mujeres escritoras (Sánchez, 2019).

\section{Método}

El corpus de este estudio está formado por los libros basados en originales en japonés que se han publicado en España, tras pasar por un proceso de traducción directa o indirecta hacia el español $\mathrm{u}$ otras lenguas oficiales (catalán, gallego y vasco). No se limita a la literatura, sino que se incluyen también, como objeto de estudio novedoso, los libros de géneros no literarios. Para el estudio, se ha excluido solamente el cómic (manga) por el formato característico en el que cada título se compone de numerosos tomos, difícil de equiparar a los libros para contabilizarlos conjuntamente. A pesar de esto, hemos consultado datos de este género en Bernabé (2019), como forma de contextualizar algunas publicaciones.

El estudio está basado en datos principalmente cuantitativos, que abarcan todas las publicaciones encontradas que se corresponden a los criterios mencionados, desde la primera publicación de la que tenemos constancia, en 1904, hasta el año 2014. Esto supone un total de 976 publicaciones, recuento del cual se excluyen reediciones, con lo que las cifras se corresponden al número de traducciones distintas. Solamente en el apartado sobre autores más traducidos se ha tenido en cuenta el número de ediciones.

Para recopilar la información, se han usado principalmente las bases de datos del ISBN y de la Biblioteca Nacional de España. ${ }^{1}$

Para este análisis, hemos clasificado las traducciones en dos grandes bloques: "literatura" y "otras

1 Para más detalles sobre la metodología y fuentes del corpus, véase Serra-Vilella (2016, p. 60). materias", que a su vez contienen diferentes categorías. En el caso de las obras no literarias, su temática se refleja claramente en el título, la cubierta y otros paratextos, mientras que las obras literarias no siempre corresponden a una temática concreta o fácil de determinar. Por ende, las primeras se han clasificado por materia, mientras las segundas solo por género, debido a que solamente se persigue ofrecer información más detallada sobre lo que se ha traducido, en tanto que no observamos una relación clara entre los géneros literarios y el contexto sociocultural.

Para observar la relación entre las traducciones y el contexto sociocultural, cuando abunda el número de obras en una categoría o época concreta, hemos buscado trabajos que ahonden en la introducción, en España, de las manifestaciones culturales pertinentes, como, por ejemplo, las artes marciales, el budismo y el manga, entre otros, para comprobar $\mathrm{si}$ se pueden establecer vínculos.

\section{Resultados}

Los resultados de este trabajo se exponen en tres apartados: en el primero, se hace una comparativa general entre géneros literarios y no literarios. En el segundo, desglosamos los libros no literarios según las materias, incluyendo una evolución diacrónica como forma de comprender mejor la vinculación entre estas traducciones y el contexto sociocultural en el que se produjeron. Por último se presentan los autores más traducidos, como elemento que también aporta información acerca de las dinámicas de circulación de textos.

\section{Evolución diacrónica: comparativa entre literatura y otras materias}

En este apartado comparamos de forma cuantitativa los dos grandes bloques en los que se divide el corpus. Inicialmente contrastamos el número de traducciones, en períodos de cinco años, agrupadas según se trate de géneros literarios o no. Luego, en las primeras etapas, debido al escaso número de títulos, comentamos los datos por décadas. 


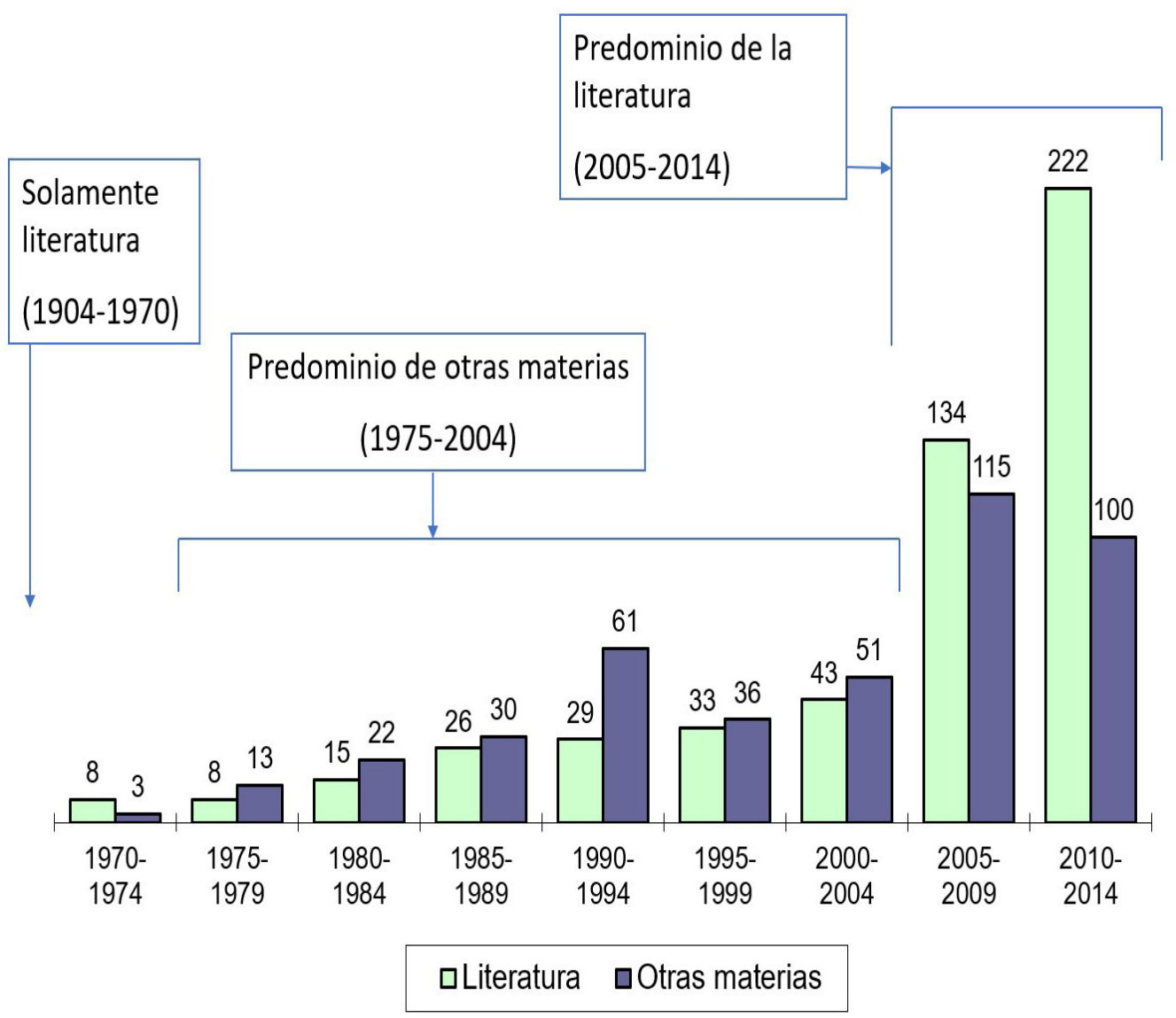

Figura 1 Número de traducciones por tipología textual (1970-2014)

Además, explicamos la evolución de las cifras en relación con aspectos destacados como, por ejemplo, la concentración de las publicaciones en unas materias concretas.

El número total de traducciones de literatura es 545 ( $55 \%$ del total), una cifra ligeramente superior a las traducciones de otras materias, que son en total 431 ( $45 \%)$.

Hasta 1970, solo encontramos publicaciones de tipo literario, y en un número muy reducido. En los años 1904 y 1909 se producen las 3 primeras traducciones; posteriormente, 2 en los años veinte y 2 en la primera mitad de los años treinta. No encontramos ninguna publicación en la segunda mitad de esa década, coincidiendo con la guerra civil.
Entre 1940 y 1944 hallamos 3 traducciones, y solamente 3 más en los siguientes 15 años. ${ }^{2}$ En la primera mitad de la década de los sesenta, se observa un repunte, con 9 traducciones, y 5 en la segunda mitad de esa década. A partir de 1970, empieza a aumentar de forma amplia el número de traducciones, como se muestra en la Figura 1. Hemos decidido excluir de la figura los datos anteriores a 1970, por dos motivos: el reducido número de publicaciones, y el hecho de que para ese período se trata solamente de literatura y, por lo tanto, no se presta a comparar libros literarios y de otras materias, que es el principal propósito de este gráfico.

2 Para más detalles sobre las primeras traducciones del japonés en España, véase Serra-Vilella (2016, pp. 111-114). 
En el periodo 1970-1974 encontramos solo 3 traducciones de géneros no literarios, pero en el siguiente (1975-1979) sobrepasan la literatura (13 frente a 8), una tendencia que perdura en los años siguientes. La mayoría (11 de 13) son de artes marciales, concretamente de karate y judo.

Para la década de los ochenta, el número de publicaciones no literarias supera ligeramente a la literatura. En esta etapa vemos también un gran número de libros de artes marciales (10 de 52), publicaciones infantiles (21) y de religión (14), además de algunos libros de otras materias, como agricultura, tecnología y empresa. Muchos de estos libros, tanto de artes marciales como infantiles, forman parte de series, lo que se relaciona sin duda con el gran volumen de publicaciones. En el caso de los libros infantiles, encontramos además un gran número publicados en castellano y en catalán y otras lenguas del Estado, lo cual explica estas cifras, pues existen dos o tres traducciones correspondientes a un mismo original.

En la primera mitad de la década de los noventa vuelve a destacar el número de publicaciones no literarias, que supera en más del doble la literatura. Más de un tercio (23 de 61) son de gestión empresarial, publicadas casi todas por la editorial TGP Hoshin. También hay 18 libros infantiles, 10 de artes marciales y 6 de religión.

En los siguientes tres períodos de 5 años, es decir, la segunda mitad de la década de los noventa y la primera década del siglo XXI, el número de traducciones de ambas categorías es similar, con las traducciones literarias superando ligeramente las otras en el período 2005-2009.

En el período 2010-2014 hay un gran aumento de traducciones literarias, duplicando las de otras materias. Esto no solo es una muestra de un interés creciente por la literatura japonesa, sino que también es un reflejo del panorama editorial que hay detrás, con la aparición de tres editoriales dedicadas a Japón: Chidori, Quaterni y Satori. Estas tres editoriales suman un total de 63 publicaciones ( 8 títulos,
26 y 29, respectivamente), lo que supone más de una cuarta parte de las traducciones literarias publicadas en este periodo. Estos datos coinciden con Iglesias (2019) sobre la imagen de Japón en España, que apunta al 2003-2004 como punto de inflexión hacia un renovado interés por el "exotismo de Oriente” (Iglesias, 2019, p. 735) después de un periodo de imágenes más negativas, en relación con el declive económico de los años noventa (p. 693), que se vinculó en la prensa con "algún tipo de falla cultural" (p. 694).

Por otra parte, como señalamos antes, la literatura goza de gran prestigio a nivel académico y social, y en nuestro corpus representa un porcentaje de las traducciones ligeramente superior a la mitad. Por lo tanto, supone una parte importante de las traducciones que se realizan.

Existen algunos trabajos que han aplicado categorías temáticas para el estudio de corpus literarios traducidos, como, por ejemplo, Torres-Simon (2015), que analizó las traducciones de literatura coreana en Estados Unidos. Sin embargo, clasificar las obras literarias por materias es una tarea complicada y con un importante componente de subjetividad, especialmente para un corpus tan extenso como el presente, por lo que hemos optado por presentar una somera clasificación por géneros, a modo informativo.

Para ello, nos basamos en los tres géneros básicos: poesía, teatro y narrativa, este último dividido en novela y cuento (véase la Figura 2). Hemos añadido algunas categorías más para las obras que no encajaban en ninguno de estos grupos: ensayo, textos clásicos (textos antiguos, principalmente de temática épica o folclórica), literatura juvenil y textos biográficos.

La novela es el género que cuenta con más publicaciones, superando la mitad, lo cual no es una característica extraordinaria de las traducciones del japonés, sino una tendencia general en la publicación literaria. Según las cifras que se ofrecen en la "Panorámica de la edición española 


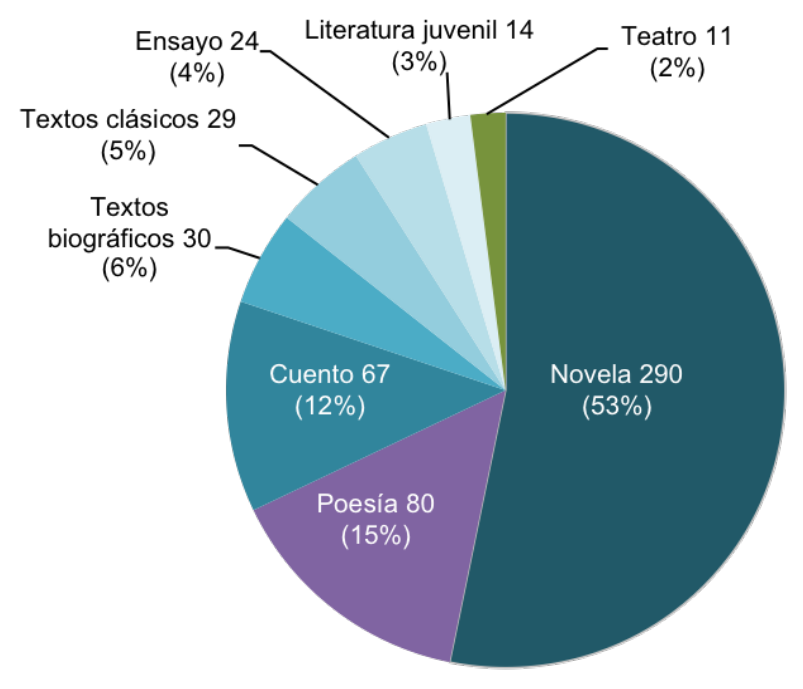

Figura 2 Publicaciones literarias por género

de libros 2013" (MECD, 2014, p. 57), la narrativa supone un porcentaje del $69,6 \%$, la poesía el 27,3 \% y el teatro el 3,1\%. En los datos de nuestro corpus vemos una gran similitud respecto a esta clasificación (a pesar de la diferencia de delimitación temporal y de objeto de estudio, la gran cantidad de datos de ambas fuentes nos parecen suficientes para una comparación a rasgos generales): la narrativa, en la que solo con el fin de posibilitar la comparación, hemos agrupado el porcentaje de las dos categorías que tiene nuestro corpus: novela y cuento, supone el $65 \%$, la poesía el $15 \%$ y el teatro el $2 \%$. Si lo comparamos con el caso de las traducciones del chino (Rovira-Esteva, 2014, p. 5), observamos una tendencia general similar: la novela y el cuento suman el $62 \%$, y la poesía, el $22 \%$.

\section{Temáticas en las traducciones no literarias}

Las traducciones de libros correspondientes a géneros no literarios suponen una parte importante de este estudio. En primer lugar, recordamos el ámbito de nuestro corpus: se trata de traducciones al español de libros japoneses, por lo que no se han incluido libros de materias relacionadas con Japón si no existe un original japonés detrás, es decir, si se han escrito originalmente en español, inglés, etc.

La distribución por materias puede ayudar a entender qué tipo de libros se seleccionan para traducir y cómo esta selección puede influir en la imagen que se tiene de Japón en la cultura receptora. Para facilitar una visión de conjunto y una organización de la información, hemos usado unas categorías genéricas basadas en la clasificación decimal universal $(\mathrm{CDU})^{3}$ y unas subcategorías más específicas, que hemos creado con base en el material encontrado y que ofrecen una información más concreta en cuanto al análisis de las temáticas que se han traducido (véase la Tabla 1 ).

La categoría que agrupa varias materias en el ámbito de las ciencias sociales incluye 60 títulos, seguida de las materias artísticas, que incluyen 40 , mientras que las ciencias aplicadas solamente suman 15 volúmenes. La subcategoría con más títulos es la de libros infantiles (142), seguida de artes marciales (102) y religión (62). También destacan los libros de empresa (43) y dibujo (23), seguidos en menor medida de los de desarrollo personal (17) y los cuentos populares (13).

Lo primero que llama la atención es que la categoría infantil ocupe la primera posición, con una cifra que supone el 31,6\% del total de libros no literarios, lo que se explica por varios factores: por un lado, la popularidad del cómic japonés puede haber influido en la importación de otros libros ilustrados; por otro, muchos de los libros infantiles hacen parte de series, lo que puede fomentar que se opte por traducir una serie entera o varios ejemplares. Creemos, por tanto, que el formato es un factor importante en la interpretación de este alto número de ejemplares.

Finalmente, queremos hacer mención también a los datos sobre libros infantiles en el ámbito de la publicación de libros en España. Según la "Panorámica de la edición española de libros 2013”, entre los libros traducidos ese año, la submateria infantil y juvenil representa aproximadamente el $22 \%$ del total, superada solo por la materia de creación literaria

3 La CDU es un método de clasificación usado en catálogos de bibliotecas universitarias y nacionales como la Biblioteca Nacional de España. También nos hemos basado en la “Tabla de materias" de la Agencia Española del ISBN (s. f.). 
Tabla 1 Número de traducciones por categorías y subcategorías

\begin{tabular}{|c|c|c|}
\hline Disciplina & Temas traducidos* & $\begin{array}{l}\text { Cantidad de } \\
\text { traducciones }\end{array}$ \\
\hline \multirow{5}{*}{$\begin{array}{l}\text { Ciencias } \\
\text { sociales }\end{array}$} & Empresa & 43 \\
\hline & Cuentos populares** & 13 \\
\hline & Economía & 2 \\
\hline & Derecho & 1 \\
\hline & Sociedad & 1 \\
\hline \multirow{4}{*}{$\begin{array}{l}\text { Ciencias } \\
\text { aplicadas }\end{array}$} & Medicina & 5 \\
\hline & Agricultura & 4 \\
\hline & Tecnología & 4 \\
\hline & Cocina & 2 \\
\hline \multirow{6}{*}{ Artes } & Dibujo & 23 \\
\hline & Arquitectura & 9 \\
\hline & Origami & 4 \\
\hline & Manualidades & 2 \\
\hline & Cine & 1 \\
\hline & Moda & 1 \\
\hline \multirow{7}{*}{ Otras } & Infantil ${ }^{* * * *}$ & 142 \\
\hline & Artes marciales & 102 \\
\hline & Religión & 62 \\
\hline & Desarrollo personal & 17 \\
\hline & Filosofía & 9 \\
\hline & Estudios literarios & 2 \\
\hline & Ciencias naturales & 1 \\
\hline
\end{tabular}

* En negrita los cinco temas más traducidos

** En la clasificación CDU, los cuentos populares aparecen en esta categoría como folklore. Estimamos adecuado diferenciarlos de los libros infantiles, por la amplia variedad de público al que pueden dirigirse los primeros según el formato, mientras que los segundos se dirigen a un público específico, como se observa por el protagonismo de las ilustraciones y el gran tamaño de la letra.

*** Hemos decidido diferenciar la literatura juvenil de los libros infantiles, dado que en el primer caso simplemente tiene un destinatario específico, mientras que en el segundo suele predominar la ilustración por encima del texto, entre otras características que les distancian del concepto de literatura.

(MECD, 2014, pp. 118-126). Así pues, vemos que el elevado número de traducciones en la categoría de libros infantiles es una tendencia general y no específica de las traducciones del japonés.
Otro hecho destacable es el gran número de publicaciones de artes marciales, que ocupan el segundo lugar. La cultura guerrera de Japón, que se materializa en la figura del samurái, es uno de los temas más estereotípicos de la cultura japonesa. Los libros relacionados con este tema se dividen en dos grandes grupos: los que tratan de artes marciales principalmente como forma de entrenamiento físico y los que se ocupan de la cultura guerrera desde un punto de vista más espiritual. Estos últimos representan casi una cuarta parte de esta subcategoría, entre los cuales destacan dos series de karate. En cuanto a los libros sobre la cultura guerrera, resaltan las numerosas retraducciones del Gorin no sho de Miyamoto Musashi y del Hagakure de Yamamoto Tsunetomo.

En la subcategoría de religión hay 62 libros, de los cuales casi la mitad son sobre budismo zen o cuestiones relacionadas. Este elevado número de publicaciones nos recuerda el comentario de Mas López (2007, p. 36), para quien los valores occidentales habían entrado en crisis y se recurrió a Asia en busca de valores espirituales. Aunque se refiere al periodo posterior a la Primera Guerra Mundial, en la que Japón demostró por primera vez su poder militar a las potencias occidentales, consideramos que es plenamente aplicable a épocas posteriores como, por ejemplo, cuando la economía de Japón pasó a ser una de las primeras del mundo. El éxito, ya sea militar o económico, se intenta relacionar a menudo con la idiosincrasia de un pueblo, lo que puede motivar un interés en los valores espirituales que rigen esa cultura.

A continuación, en la categoría de ciencias sociales, destacan los libros sobre organización y gestión de empresa. Si observamos el detalle de los títulos que engloba esta materia, la mayor parte (36 sobre 43) han sido publicados por la editorial TGP Hoshin, mientras que los siete restantes han sido publicados por 4 editoriales diferentes. En esta categoría se incluyen también los cuentos populares, con trece obras. 
El resto de materias en el grupo de ciencias sociales tienen solo 4publicaciones: concretamente, el Código civil japonés (Domingo y Hayashi [eds.], 2000) y tres publicaciones que tratan de temas relacionados con economía y sociedad: Teoría económica de la sociedad moderna (Morishima, 1981), La economía japonesa en una época de transición (Hosono, 1995) y Toyota y Nissan: la otra cara de la productividad japonesa. El punto de vista de los trabajadores (Kamata, 1993). El primero se enmarca dentro del periodo del llamado "milagro japonés" (años sesenta-ochenta), en el que la economía de Japón experimentó un gran crecimiento, mientras que los otros dos se publican en la década de los noventa y reflejan enfoques posteriores. Del tercer libro destacaríamos el hecho de que la editorial es Columna/Comissió Obrera Nacional de Catalunya, es decir, es una traducción propiciada desde la cultura meta, posiblemente por el carácter innovador que presenta en contraste con otras publicaciones o noticias sobre la economía japonesa, que ponen énfasis en el éxito económico de este país.

En la categoría de artes destacan los libros de dibujo, concretamente 23, que pertenecen a la serie "Cómo dibujar manga". El gran número de libros de este tema creemos que está relacionado no solo con el hecho de tratarse de una serie, sino también con la gran difusión que ha tenido el género desde la década de los noventa en España (Tajada Sanz, 2007, p. 479).

A continuación, encontramos 9 libros de arquitectura, 4 de origami, 2 de manualidades, 1 de cine y 1 de diseño de moda (a pesar de que en la CDU, "moda" aparece en el ámbito de las ciencias sociales, en este caso, como el mismo título del libro incluye las palabras "ilustración” y "dibujo", parece más afín al campo de las artes). Este último, Ilustración de moda contemporánea. Iniciación a las técnicas de dibujo, de N. Watanabe (2009), destaca por el hecho de no tener unas características que lo definan como libro japonés, a diferencia de muchas otras publicaciones que, como hemos visto, tratan temas muy típicos de Japón o en los que el mismo título incluye una referencia directa al país de procedencia.
En la subcategoría de desarrollo personal encontramos un número amplio de libros (17 en total), más que de filosofía propiamente dicha (9). Entre estos está la serie Brain trainer de Kawashima Ryuta, que comprende cinco publicaciones entre 2007 y 2012, seguramente en relación con la popularidad de esta serie como juego de Nintendo, y varios libros de autoayuda, como, por ejemplo: La ley del espejo. Una regla mágica que resuelve cualquier problema en la vida (Noguchi, 2010).

En la categoría de ciencias aplicadas hay 5 libros relacionados con la medicina (2 de odontología, 1 de fisioterapia y 1 de cardiopatía), 4 de tecnología, 4 de agricultura y 2 de cocina. De tecnología, hay 1 libro sobre el shinkansen, el tren de alta velocidad, y 3 de informática. Hay 4 libros sobre la agricultura natural.

En cuanto a libros de cocina, llama la atención el bajo número de libros de una materia que goza de bastante popularidad. Sin embargo, la mayoría libros de esta materia que se encuentran en librerías no son traducciones del japonés. Entendemos que optar por un texto escrito en la misma cultura del receptor, en vez de una traducción, puede tener motivaciones técnicas, como, por ejemplo, adaptar las recetas a los ingredientes locales.

Por último, hay una sola traducción en el ámbito de las ciencias naturales y dos de estudios literarios, una sobre el $n \bar{o}$, teatro tradicional japonés, y una titulada Los "sonetos de la muerte" de Gabriela Mistral (Tamura, 1998), un caso curioso, ya que se trata de un estudio literario sobre una escritora española escrito originalmente en japonés.

En resumen, las materias con mayor número de libros son, en orden descendente: infantil $(31,6 \%),{ }^{4}$ artes marciales $(22,7 \%)$, religión (13,8\%), empresa $(9,6 \%)$, dibujo $(5,1 \%)$ y desarrollo personal $(3,8 \%)$. Por lo tanto, las tres materias con más libros representan unos dos tercios (68\%) del total de 450 libros clasificados en

4 Porcentajes sobre el total de libros no literarios. 
diferentes materias. Creemos que la diferencia tan grande entre estas materias y el resto no es simplemente casualidad, sino que está relacionada con la imagen predominante sobre este país.

Como hemos visto, la temática de la espiritualidad se encuentra en varias de las materias: en religión, como parte intrínseca, pero, además, en algunos libros de artes marciales, de filosofía y especialmente en desarrollo personal. Asimismo, varios libros contienen la palabra "espiritual” en el título: El corazón del Aikido: enseñanzas espirituales (Sunadomari, 2007), Haiku-dō: el haiku como camino espiritual (Haya, 2007), La espiritualidad de los cuentos populares japoneses (Masuda, 2007) y Lecciones espirituales para los jóvenes samuráis $y$ otros ensayos (Mishima, 2001). Esto concuerda con una imagen de Oriente o de Japón vinculada a la espiritualidad, que mencionan Iglesias (2019, p. 731) y Mas López (2007, p. 36).

Para poder contrastar los datos con el contexto sociocultural, juzgamos importante observar el número de traducciones de estas categorías en un gráfico de distribución diacrónica (véase la Figura 3).
De entre las cinco materias con más libros publicados, las tres primeras (infantil, artes marciales y religión) muestran un recorrido continuado en el tiempo, mientras que las otras dos están concentradas en periodos de tiempo concretos (empresa y dibujo). A grandes rasgos, la Figura 3 muestra un especial aumento de títulos entre 1990 y 1994, y una disminución entre 1995 y 2004 . Es interesante comparar estas tendencias con los datos del trabajo de Iglesias (2019), que analiza las imágenes del país nipón en la prensa española y afirma que

\section{Si 1995 fue el año en el que Japón, simbólicamente, dejó de ser el principal referente del desarrollo económico y la modernidad, el 2003-2004, precisamente, podría consi- derarse inscrito en la consolidación de un nuevo ciclo de pasión por el exotismo de Oriente (Iglesias, 2019, p. 735).}

El número de libros infantiles aumenta a principios de los años ochenta y noventa, disminuye en forma drástica en la segunda mitad de la década de los noventa y principios de siglo, y después se incrementa de manera espectacular entre 2005 y 2009, y moderadamente en el periodo posterior. Se observan aquí similitudes con los datos sobre publicación de manga de Bernabé (2019), que

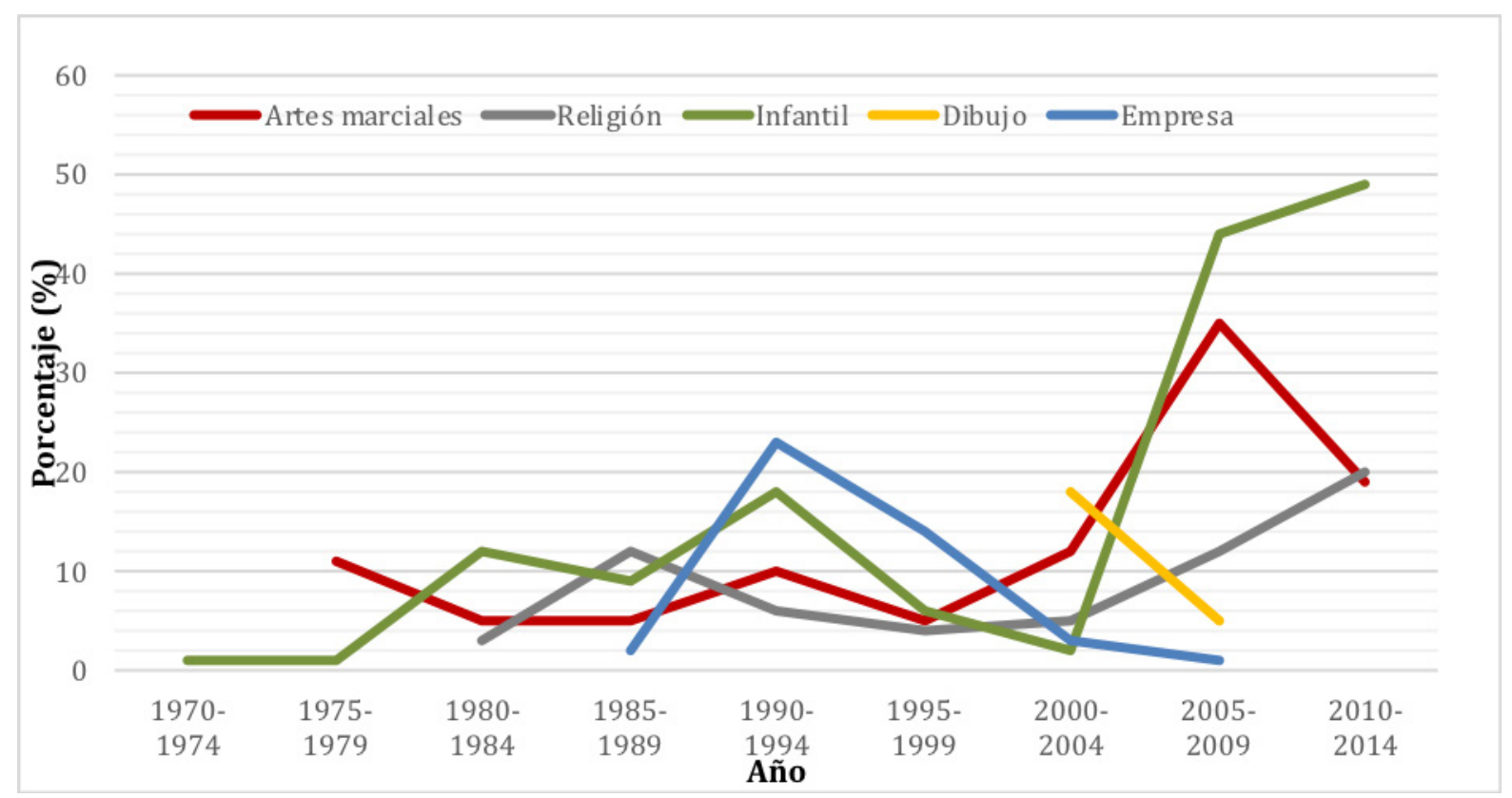

Figura 3 Materias con más publicaciones: distribución diacrónica 
muestran un crecimiento sostenido de este género desde 2001 hasta 2008, con un significativo declive entre 2010 y 2014, y una posterior recuperación hasta la actualidad. Este declive coincide en el tiempo con una notable desaceleración de las publicaciones infantiles, después de haberse incrementado en forma espectacular en el periodo anterior.

Los libros de dibujo tienen una relación clara con el fenómeno del manga, ya que no solo tratan sobre este estilo de dibujo, sino que también todos se han publicado durante la primera década del dos mil, en mayor número en la primera mitad. Concretamente, se trata de una serie titulada "Cómo dibujar manga", que se publicó entre 2001 y 2006, coincidiendo con el aumento de este tipo de cómic (Bernabé, 2019). El hecho de tratarse de una serie concentrada en unos años concretos implica que su representación en la figura no resulta especialmente relevante, pero decidimos incluirla por coherencia con su pertenencia a las 5 materias más traducidas.

En el caso de las artes marciales, el inicio de las publicaciones, situado en los años setenta, coincide con el auge de este tipo de deportes en España (Pérez y Gutiérrez, 2008, p. 30). Después de un cierto número de traducciones a finales de los años setenta, disminuyen ligeramente, con un pequeño aumento a principios de los años noventa. En la primera década de este siglo se produce un gran incremento de los libros de artes marciales, pero en los últimos 5 años el número disminuye a casi la mitad del período anterior. El inicio del crecimiento hacia el año 2000 coincide con la "consolidación de las artes marciales" que apunta Iglesias (2019, p. 489), al analizar su presencia en la prensa en esos años.

En cuanto a la temática religiosa, se trata de libros en su mayoría relacionados con el budismo (cerca de la mitad de ellos, concretamente, con el budismo zen). Teniendo en cuenta que en el año 1975 termina la dictadura franquista, que tenía una fuerte vinculación con el catolicismo, no parece una coincidencia encontrar las primeras publicaciones en los años ochenta. En 1977 se abrió el primer centro budista del país y en 1980 se promulgó la Ley de Libertad Religiosa (Díez de Velasco, 2013, p. 45). En la segunda mitad de los años ochenta vemos un pico y más tarde, el número de publicaciones se mantiene comparativamente bajo, hasta los últimos diez años, en el que experimenta un aumento progresivo.

En cuanto a los libros de empresa, empiezan a aparecer en la segunda mitad de los años ochenta y son especialmente numerosos en la primera mitad de los años noventa. Esto se puede relacionar con el llamado "milagro japonés", que supuso un fuerte crecimiento económico y, por tanto, el interés internacional por la economía y los métodos empresariales de este país. Observamos una relación entre estas cifras y los datos del trabajo de Iglesias (2019), que analiza las imágenes del país nipón en la prensa española y afirma que "los años setenta y ochenta, coincidieron con una España que buscaba modelos de éxito en los que inspirarse" (p. 468), y que en los años ochenta abundan los elogios a Japón, "particularmente cuando se abordan cuestiones relacionadas con el mundo empresarial y el desarrollo económico español" (p. 586). La progresiva disminución y desaparición de esta materia coincide asimismo con el "fin del modelo japonés" (p. 681), vinculado no solo a la desaceleración económica de Japón, sino también a los problemas con multinacionales japonesas en España en ese periodo.

\section{Autores más traducidos}

La autoría es un parámetro que igualmente valoramos como interesante en cuanto al estudio sobre qué se traduce. Hemos diferenciado dos posibles formas de recuento: según el número de ediciones y según el número de originales traducidos. Nos parece relevante diferenciar estos dos conceptos, pues hay autores que se han publicado mucho, pero sin una diversidad de originales tan grande, y al revés. Como veremos, las dos clasificaciones arrojan resultados diferentes. 
En primer lugar, en lo que respecta al número de ediciones publicadas por autor, hemos calculado las primeras 10 posiciones (véase la Figura 4). No es sorprendente que la primera posición la ocupe Haruki Murakami, quien no solo es el autor más traducido, sino que también cuenta con un total que se aproxima al centenar de ediciones, incluyendo las publicaciones en todas las lenguas del Estado. Este novelista contemporáneo ha adquirido gran popularidad a nivel internacional. Además de la escritura, traduce literatura inglesa al japonés, y en Japón se le considera un autor muy occidentalizado, tanto por el estilo de su escritura como por la alusión a referentes de la cultura anglosajona, especialmente nombres de canciones que utiliza para los títulos de algunas de sus novelas. Su estilo literario tiene influencias de la lengua inglesa, lo que el autor mismo confirma (Makino, 2014, p. 6). Recibió el Premio Internacional de la Generalitat de Catalunya por "constituir un puente literario entre Oriente y Occidente” (Redacció ara, 2011; mi traducción).
Le siguen otros autores que asimismo publican principalmente novela: Yukio Mishima, Yasunari Kawabata, Sōseki Natsume, Kenzaburō Ōe, Jun'ichirō Tanizaki (por orden descendente) y, en décima posición, Shūsaku Endō. Los autores que han recibido premios Nobel, Kawabata y Ōe, ocupan la tercera y la quinta posición, respectivamente, lo cual reafirma la importancia de este premio como factor en la selección de obras a traducir. Cabe añadir que la mayor parte de las publicaciones de estos dos autores se produjo después de la concesión del premio (Serra-Vilella, 2016, pp. 293-295, 314-316). El resto son autores consagrados de la literatura japonesa, es decir, el único autor contemporáneo que aparece en esta lista es Murakami. Por lo tanto, vemos una dualidad entre un único autor contemporáneo y el resto, que son autores considerados clásicos.

A partir de la séptima posición empiezan a aparecer autores de géneros diferentes a los literarios.

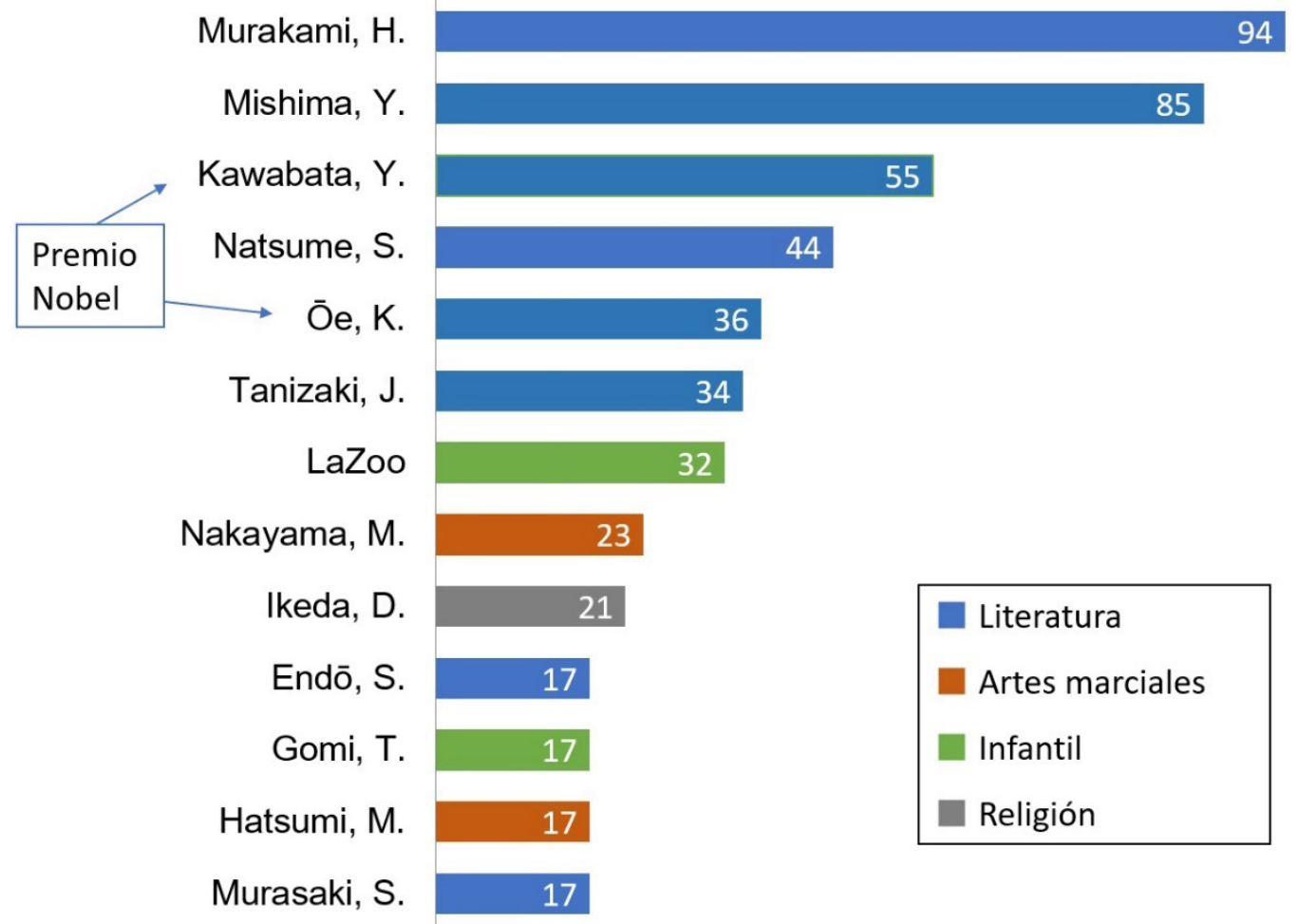

Figura 4 Autores con mayor número de ediciones publicadas 
En la séptima y la undécima posición encontramos autores de libros infantiles: LaZoo, nombre artístico de un grupo de dibujo, y Tarō Gomi, prolífico autor de libros infantiles. En la octava y en la duodécima posición hallamos representantes de la materia de artes marciales, Masatoshi Nakayama y Masaaki Hatsumi, que pertenecen a la disciplina del karate y a la escuela Bujinkan, respectivamente. En la novena posición está Daisaku Ikeda, presidente de la rama budista Soka Gakkai. Esta organización ha realizado un gran esfuerzo de difusión internacional y dentro de Japón tiene una fuerte presencia, incluyendo la vinculación con un partido político. Este autor pertenece a otra de las materias más traducidas en nuestra base de datos, los libros de religión (budismo).

Por último, entre los que ocupan la décima posición, encontramos a Murasaki Shikibu, la única mujer que ha entrado en esta clasificación. Se trata de una de las autoras más destacadas de la litera-
A continuación, la segunda forma de clasificación restringe el recuento solo a número de originales, es decir, excluye reediciones y retraducciones de los mismos originales, como también traducciones de un mismo título a diferentes lenguas oficiales. De esta forma, podemos observar cuántas obras se han traducido de cada autor (véase la Figura 5).

Un número considerable de nombres se repiten respecto a la Figura 4, en la que se mostraba el número de ediciones, aunque las posiciones son muy diferentes. Lo primero que llama la atención es que tanto Murakami como los premios Nobel Ōe y Kawabata bajan de posición (cuarta, sexta y octava, respectivamente). Es decir, se han hecho muchas ediciones pero, comparativamente, el número de originales escogidos para traducir no es tan alto.

Los escritores que cuentan con más obras traducidas son Natsume y Mishima, ambos muy valorados en la literatura japonesa. Los autores de libros de artes marciales, Nakayama y Hatsumi pasan a la

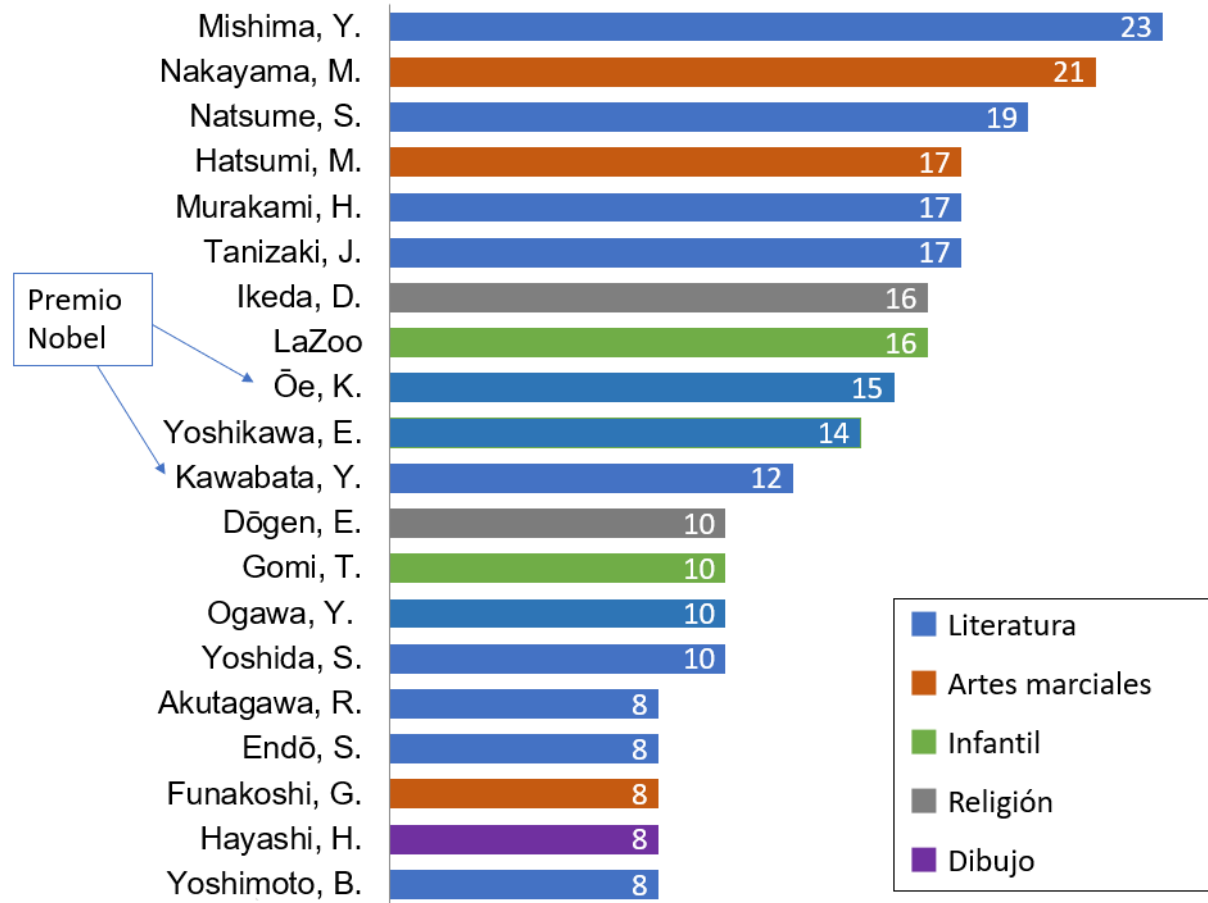

Figura 5 Autores con más obras traducidas 
segunda y la cuarta posición. En la quinta posición encontramos a Ikeda, de temática religiosa, y LaZoo, de temática infantil.

A partir de la séptima posición aparecen autores nuevos respecto al anterior recuento: un autor de libros sobre budismo (Eihei Dōgen), uno de karate (Gichin Funakoshi) y uno de libros de dibujo (Hikaru Hayashi). También hay algunos escritores: Eiji Yoshikawa, que escribe novelas de tipo histórico (sobre samuráis), Ryūnosuke Akutagawa, el prestigioso autor de relatos, y, por último, tres autores contemporáneos: las novelistas Yoko Ogawa y Banana Yoshimoto, y el autor de literatura juvenil Sunao Yoshida. De estos, Ogawa y Yoshimoto son las dos únicas mujeres que aparecen en esta clasificación.

\section{Discusión y conclusiones}

La traducción del japonés en España ha seguido una larga trayectoria, en la que encontramos prácticamente a partes iguales literatura y otros tipos de libros ( 55 y $45 \%$, respectivamente). Esto muestra que los libros no literarios, a pesar de no haber sido tan estudiados como la literatura, tienen un peso relevante a nivel de publicaciones.

A través de este estudio hemos podido constatar que se observa una relación entre las traducciones y el contexto en el que se produjeron. Por una parte, entre las primeras traducciones se observa un vacío entre 1936 y 1940, coincidiendo con la guerra civil. Por otra parte, la distribución en el tiempo de las obras pertenecientes a las materias más traducidas permite ver una relación de estas con las circunstancias históricas. En cada década destaca una materia en concreto: las artes marciales en los años setenta, los libros de religión e infantiles en los años ochenta y libros sobre empresa en los años noventa.

Como hemos explicado en el apartado "Temáticas en las traducciones no literarias", las publicaciones de artes marciales coinciden con el inicio de esta práctica y su implementación en España.
Posteriormente, con el fin de la dictadura y la Ley de Libertad Religiosa (España, Ley Orgánica 7/1980, de 5 de julio, de Libertad Religiosa), se observa el inicio de publicaciones sobre budismo. También en la década de los ochenta hay un gran número de publicaciones infantiles, que se incrementa en los años noventa, coincidiendo con el auge del manga. El gran número de libros sobre ciencias empresariales en los años noventa se puede vincular con la imagen de Japón como una economía fuerte, en relación con el llamado "milagro japonés", que protagonizó las referencias a ese país en la prensa española hasta esa década (Iglesias, 2019, pp. 691-692).

La distribución por materias de los libros no literarios es especialmente relevante para observar la imagen del país nipón que se desprende de la selección de obras a traducir. Hemos constatado una gran diversidad de materias, pero mientras que muchas cuentan con un número extremadamente reducido de títulos, otras pocas agrupan gran cantidad de libros, lo cual nos remite a la recurrencia a la simplificación y los tópicos en la representación del Otro oriental.

Las tres materias con más publicaciones representan el 68,1\% del total de 450 obras no literarias (infantil, $31,6 \%$; artes marciales, $22,7 \%$, y religión, $13,8 \%$ ), seguidas de las categorías de empresa (9,6\%), dibujo (5,1\%) y desarrollo personal (3,8\%). Esta gran concentración se relaciona con la imagen que se tiene de este país y, al mismo tiempo, la selección de estas obras para traducir refuerza esta imagen, y muestra que no se trata de hechos puntuales, sino que pueden vincularse a modas o corrientes de un momento concreto.

La primera categoría, los libros infantiles, se puede vincular con el manga, un icono moderno muy relevante, y los libros de dibujo publicados están directamente relacionados con este tipo de cómic. Las artes marciales suponen un vínculo con la imagen del samurái o guerrero, y la fuerza económica que marcó la imagen del Japón de la posguerra se observa en la categoría de empresa. 
Finalmente, la espiritualidad es asimismo un icono que se suele relacionar con el "Oriente" y en especial con Japón, lo cual se ve vinculado no solo con la materia de religión, sino también con los libros de desarrollo personal y una parte de los libros de artes marciales, como se observa incluso en los títulos de algunas obras.

Por lo tanto, se ve confirmada la hipótesis de partida, pues la selección de obras traducidas muestra una tendencia a determinados temas que coinciden con la imagen de ese país, según hemos podido contrastar con varios estudios, el más extenso de ellos que repasa las imágenes de Japón en la prensa española desde hace un siglo (Iglesias, 2019). Esta selección que llega a las librerías, al mismo tiempo, refuerza la imagen preexistente.

Por otra parte, el hecho de que la temática religiosa sea una de las más traducidas muestra una función enriquecedora de la traducción a nivel espiritual o humanista, imprescindible para "la creación de la sensibilidad de cualquier sociedad" (Orozco, 2000, p. 74). Es decir, la transmisión de valores parece una parte intrínseca en la naturaleza de la traducción.

La distribución por géneros literarios, con el predominio de la novela (53\%), seguida de la poesía (15\%) y el cuento (12\%), parece inscribirse en una tendencia general si comparamos estos datos con las traducciones del chino (Rovira-Esteva, 2014, p. 5) y los datos de publicaciones en España (MECD, 2014). Esto muestra la relación de las traducciones con otros sistemas literarios del mismo país, lo que confirma la necesidad de estudiar la traducción como parte de un polisistema.

Para tener una mejor perspectiva sobre qué se traduce, hemos analizado además a los autores que se seleccionan para traducir. En cuanto al número de ediciones, la primera posición la ocupa Murakami, probablemente el autor japonés más popular en la actualidad en nuestro país y en Occidente, seguido de novelistas consagrados: Mishima, Kawabata, Natsume, Ōe, Tanizaki y Endō. Los autores que recibieron un premio Nobel se encuentran entre los más publicados, reafirmando la trascendencia de este galardón sobre la traducción, lo cual también se observa en el caso de otras lenguas, y es una muestra de los condicionantes socioculturales que intervienen en la selección de obras para traducir.

En ambas clasificaciones (por ediciones y por obras traducidas) encontramos representantes de las materias más traducidas (artes marciales, budismo y libros infantiles). En lo que respecta a autoras, destaca el hecho de que solo aparecen tres mujeres entre ambas clasificaciones, y en las posiciones inferiores. Esto parece un reflejo de las relaciones de poder del sistema sociocultural en el que se han creado tanto las traducciones como los textos originales.

Como punto novedoso de este estudio, destacamos el hecho de tratar las temáticas de géneros no literarios, un ámbito muy poco estudiado. Además, como resultado más destacable, remarcaríamos el hecho de que se observa una gran concentración de obras de unas materias concretas, mientras que las otras contienen muy pocos títulos.

Como posibles líneas de investigación futuras, sería interesante conocer datos similares de otros países y poder comparar las tendencias, por ejemplo, las traducciones de literatura japonesa en los países hispanohablantes, o en diferentes países de Europa, por lo que esperamos poder ampliar nuestra investigación en el futuro e inspirar a expertos de otros países.

\section{Referencias}

Agencia Española del IsBn (s. f.). Tabla de materias. https:// www.agenciaisbn.es/web/archivos/TablaCDUISBN.pdf

Amossy, R. (1991). Les idées reçues. Sémiologie du stéréotype. Nathan.

Bernabé, M. (2019). Estadisticas manga 2019. http://www. mangaland.es/2019/12/estadisticas-manga-2019/

D’hulst, L. (2010). Translation history. En Y. Gambier y L. van Doorslaer (Eds.), Handbook of translation 
studies, Volume 1 (pp. 397-405). John Benjamins. https://doi.org/10.1075/hts.1.tra5

Delisle, J. (2003). La historia de la traducción: su importancia para la traductología y su enseñanza mediante un programa didáctico multimedia y multilingüe. Íkala, 8(1), 221-235. https://revistas.udea.edu.co/ index.php/ikala/article/view/3186

Díez de Velasco, F. (2013). El budismo en España. Historia, visibilización e implantación. Akal.

Domingo, R. y Hayashi, N. (Eds.) (2000). Código civil japonés. Marcial Pons.

El Bohdidi, M. (2017). La traducción español-árabe y árabeespañol: panorama y perspectiva intercultural. Íkala, revista de lenguaje y cultura, 22(2), 271-284. https:// doi.org/10.17533/udea.ikala.v22n02a07

España, Ley Orgánica 7/1980, de 5 de julio, de Libertad Religiosa (1980). Boletín Oficial del Estado [BOE] número 177. 24 de julio de 1980. https://www.boe.es/buscar/ pdf/1980/BOE-A-1980-15955-consolidado.pdf

España, Ministerio de Educación, Cultura y Deporte (MECD). (2019). Indicadores estadisticos culturales vinculados al libro y desgloses por sexo. http://www. culturaydeporte.gob.es/dam/jcr:25965595-9814459f-83d4-7252ed431e8e/estadisticas-libro.pdf

España, Ministerio de Educación, Cultura y Deporte (MECD). (2014). Panorámica de la edición española de libros 2013. Análisis sectorial del libro. https:// www.cegal.es/wp-content/uploads/2016/05/ Panor\%C3\%A 1 mica-de-la-Edici\%C3\%B3nEspa\%C3\%B1ola-de-Libros-2013.pdf

Even-Zohar, I. (2017). Polisistemas de cultura: Un libro electrónico provisorio. Universidad de Tel Aviv, Laboratorio de investigación de la cultura. https://www. tau.ac.il/ itamarez/works/papers/trabajos/polisistemas_de_cultura2007.pdf

Gil Bardají, A. (2009). Traducir Al-Andalus: el discurso del otro en el arabismo español [de Conde a García Gómez]. Edwin Mellen Press.

Haya, V. (Ed.) (2007). Haiku-dō: el haiku como camino espiritual. Kairós.

Hosono, A. (Ed.) (1995). La economía japonesa en una época de transición. Círculo Internacional de Editores.

Iglesias Rodríguez, J. C. (2019). Imágenes del Japón en Occidente: representaciones culturales y usos sociales. De los paradigmas estadounidenses a las visiones españolas desde mediados del siglo $\mathrm{XX}$ [Tesis doctoral, Universidad de Oviedo]. http://hdl.handle. net/10651/54155
Kamata, S. (1993). Toyota i Nissan: l'altra cara de la productivitat japonesa: el punt de vista dels treballadors. Columna/Comissió Obrera Nacional de Catalunya.

Lafarga, F. (2005). Sobre la historia de la traducción en España: contextos, métodos, realizaciones. Meta: Translators' Journal, 50(4), 1133-1147. https://doi. org/10.7202/012065ar

Makino, S. (2014). Murakami Haruki no nihongo wa naze omoshiroi no ka: buntai wo chuushin ni. En S. Kubota (Ed.), 24th Annual Conference of the Central Association of Teachers of Japanese (CATJ24) Proceedings, October 5-6, 2013 (pp. 1-19). Department of World Languages, Eastern Michigan University. https://commons.emich.edu/catj/1

Mangiron i Hevia, C. (2006). El tractament dels referents culturals a les traduccions de la novel.la Botxan: la interacció entre els elements textuals $i$ extratextuals [Tesis doctoral. Universitat Autònoma de Barcelona]. http://hdl.handle.net/10803/5270

Marín-Lacarta, M. (2012). A brief history of translations of modern and contemporary chinese literature in Spain (1949-2009). 1611: Revista de historia de la traducción, (6), 1-7. https://dialnet.unirioja.es/servlet/ articulo? codigo $=5082944$

Marin-Lacarta, M. (2018). Mediated and marginalised: Translations of modern and contemporary Chinese literature in Spain (1949-2010). Meta: Journal des traducteurs, 63(2), 306. https://doi. org/10.7202/1055141ar

Mas López, J. (2007). El soft power japonés: la seducció d'Occident: El desembarcament de Japó a la modernitat. DCidob, (101), 34-38. https://www.raco.cat/ index.php/DCidob/article/view/71903

Masuda, S. (2007). La espiritualidad de los cuentos populares japoneses. Desclée De Brouwer.

Mishima, Y. (2001). Lecciones espirituales para los jóvenes samuráis y otros ensayos. La Esfera de los Libros.

Morishima, M. (1981). Teoría económica de la sociedad moderna. Antoni Bosch.

Moya Martínez, M. D. (2019). La imagen de Japón en España. Prensa, propaganda y cultura (1890-1945) [Tesis doctoral. Universidad de Córdoba]. http:// hdl.handle.net/10396/19161

Noguchi, Y. (2010). La ley del espejo. Una regla mágica que resuelve cualquier problema en la vida. Comanegra.

Ojeda García, J. R. (2017). Reflexiones en torno a la imagen de Japón difundida por la prensa española en el tránsito 
hacia el Nuevo Régimen. Mirai. Estudios Japoneses, (1), 307-316. https://doi.org/10.5209/MIRA.57120

Orozco, W. (2000). La traducción en el siglo XIX en Colombia. Íkala, Revista de Lenguaje y Cultura, 5(1-2), 73-88. https://revistas.udea.edu.co/index.php/ ikala/article/view/8026

Pageaux, D. H. (1995). Recherches sur l'imagologie: de l'Histoire culturelle á la Poétique. Revista de Filología Francesa, (8), 135-160. https://revistas.ucm.es/index.php/THEL/article/view/THEL9595330135A

Pérez Gutiérrez, M. y Gutiérrez García, C. (2008). Estudio bibliométrico: sobre las monografías de artes marciales publicadas en España (1906-2006). Revista de Artes Marciales Asiáticas, 3(4), 23-33. https://doi. org/10.18002/rama.v3i4.387

Pym, A. (1998). Method in translation history. St. Jerome.

Redacció ara (2011, marzo 18). Haruki Murakami rep el Premi Internacional Catalunya. ara. https://www.ara. cat/cultura/Haruki_Murakami-Artur_Mas-Premi_ Internacional_de_Catalunya_0_446355724.html

Rovira-Esteva, S. (2014). El papel de los paratextos en la construcción de la imagen e identidad del otro chino a través de la traducción literaria. En Foro Español de Investigación en Asia-Pacifico (FEIAP) (Contribución a un congreso). Universidad de Granada. https:// ddd.uab.cat/record/116244

Said, E. W. (1978). Orientalism. Pantheon Books.

Sánchez Martínez, S. (2019). Olvidadas antes de ser conocidas. La ausencia de mujeres escritoras en los libros de texto en la enseñanza obligatoria. Revista Prisma Social, (25), 203-224.

Serra-Vilella, A. (2016). La traducció de llibres japonesos a Espanya (1900-2014) i el paper dels paratextos en la creació de l'alteritat [Tesis de doctorado. Univer- sitat Autònoma de Barcelona]. https://hdl.handle. net/10803/387230

Serra-Vilella, A. (en prensa). La mujer japonesa en las cubiertas de las novelas traducidas. En M. Crespín Perales (Ed.), Feminismo e identidades de género en Japón (pp. 249-267). Edicions Bellaterra.

Sunadomari, K. (2007). El corazón del Aikido: enseñanzas espirituales. Arkano Books.

Tajada Sanz, C. (2007). El mercado español del manga, estado de la cuestión. En La investigación sobre Asia Pacifico en España (pp. 473-488). Universidad de Granada.

Tamura, S. (1998). Los "sonetos de la muerte" de Gabriela Mistral. Gredos.

Terol Rojo, G. (2008). El legado desconocido. En P. San Ginés (Ed.), Nuevas perspectivas de investigación sobre Asia Pacifico (pp. 231-251). Universidad de Granada.

Torres Simón, E. (2013). Translation and post-bellum image building: Korean translation into the US after the Korean war [Tesis doctoral. Universitat Rovira i Virgili]. http://hdl.handle.net/10803/145864

Torres-Simon, E. (2015). Hidden struggles: Presentations of Korea in translated Korean literature. Journal of Multicultural Discourses, 10(3), 369-384. https:// doi.org/10.1080/17447143.2015.1080713

Watanabe, N. (2009). Ilustración de moda contemporánea. Iniciación a las técnicas de dibujo. Promopress.

Widdowson, H. G. (2004). Text, context, pretext: Critical issues in discourse analysis. Blackwell Publishing Ltd. https://doi.org/10.1002/9780470758427

Zhou, X. y Sun, S. (2017). Bibliography-based quantitative translation history. Perspectives, 25(1), 98-119. https://doi.org/10.1080/0907676X.2016.1177100

Cómo citar este artículo: Serra-Vilella, A. (2021). Qué se traduce: literatura y otros libros japoneses en España, 1904-2014. Íkala, Revista de Lenguaje y Cultura, 26(2), 403-420. https://doi.org/10.17533/ udea.ikala.v26n02a09 